\title{
Regulation of the Drosophila dopa decarboxylase gene in neuronal and glial cells
}

\author{
C.J. Beall and J. Hirsh \\ Department of Biological Chemistry, Harvard Medical School, Boston, Massachusetts 02115 USA
}

\begin{abstract}
A cis-regulatory element selectively required for expression of the Drosophila melanogaster dopa decarboxylase gene (Ddc) in the central nervous system has been identified previously (Scholnick et al. 1986). Here, we show that at least one additional regulatory element is required for normal neuronal expression of $D d c$. We find that $D d c$ is normally expressed in about 125 discrete neurons and in a diffuse network comprising a subset of glial cells. The expression of in vitro-altered $D d c$ genes was studied by immunohistochemistry following germ line reintegration with P-element vectors. Normal neuron-specific Ddc gene expression requires both the initially identified element (element $I$ ) which is 60 bp upstream from the RNA start site, and an additional regulatory element located 800-2200 bp upstream. This latter element is required for neuronal expression but is not necessary for glial expression of $D d c$. We provide a model to explain how interactions between multiple regulatory elements may serve to specify cell-specific gene expression.
\end{abstract}

[Key Words: Transcriptional regulatory elements; neural gene expression]

Received March 3, 1987; revised version accepted April 27, 1987.

The central nervous system (CNS) contains a variety of cell types. Because of the varied distributions of cellular products such as neurotransmitters and receptors, it is expected that this tissue will show discrete patterns of cell-specific gene expression. Analyses of several neurally expressed genes confirm that they are expressed in complex subsets of neurons (Rosenfeld et al. 1984; Scheller et al. 1984; Bloom et al. 1985). The mechanisms generating this diversity remain to be elucidated. In this paper we examine the effects of mutations in the dopa decarboxylase gene, $D d c$, of Drosophila melanogaster to study the regulation of cell-specific expression in the CNS.

The tissue-specific expression of $D d c$ is regulated both transcriptionally and post-transcriptionally. Scholnick et al. (1986) have demonstrated that one regulatory element located between -83 and -59 relative to the $D d c$ RNA start point is selectively required for normal expression in the CNS, whereas multiple elements between -106 and -33 are necessary for normal hypodermal expression. No sequences upstream of -208 are required for normal levels of expression in either the hypoderm or the CNS, or for the normal temporal profile of developmentally regulated $D d c$ expression (Hirsh et al. 1986). The post-transcriptional regulation of $D d c$ involves alternate splicing of the unique $D d c$ primary transcript (Morgan et al. 1986). This RNA is alternately spliced in the CNS, resulting in a mRNA containing four exons, as opposed to the three-exon form expressed in the hypoderm. The CNS mRNA encodes a $D d c$ enzyme isoform containing 33-35 additional amino-terminal amino acids relative to the hypodermal isoform. No specialized functions have yet been ascribed to the enzyme isoforms.

In all of the studies mentioned above, $D d c$ expression was assayed by measurement of $D d c$ enzyme activity or transcripts in whole animals or dissected tissues. We have extended the analysis of $D d c$ expression to the cellular level by immunohistochemical staining with anti$D d c$ antibodies. $D d c$ enzyme activity in the CNS leads to the production of the putative neurotransmitters dopamine and serotonin (5-hydroxytryptamine) (Livingstone and Tempel 1983; White and Vallés 1985). Both of these compounds are localized within a small number of cells in the larval CNS. Serotonin immunoreactivity is confined to approximately 80 neurons (White and Vallés 1985; Vallés and White 1986), whereas dopa and/or dopamine are present in about 35 different neurons of the ventral ganglion and in three small clusters of neurons in the brain lobes (Budnik et al. 1986). Here, we show that the $D d c$ gene product is localized primarily within these neurons, though we also detect $D d c$ in a subset of glial cells. We also demonstrate the existence of a new cis-regulatory element, necessary for normal neuronal expression. The function of this regulatory element is not detectable in whole-tissue assays, since mutant $D d c$ 

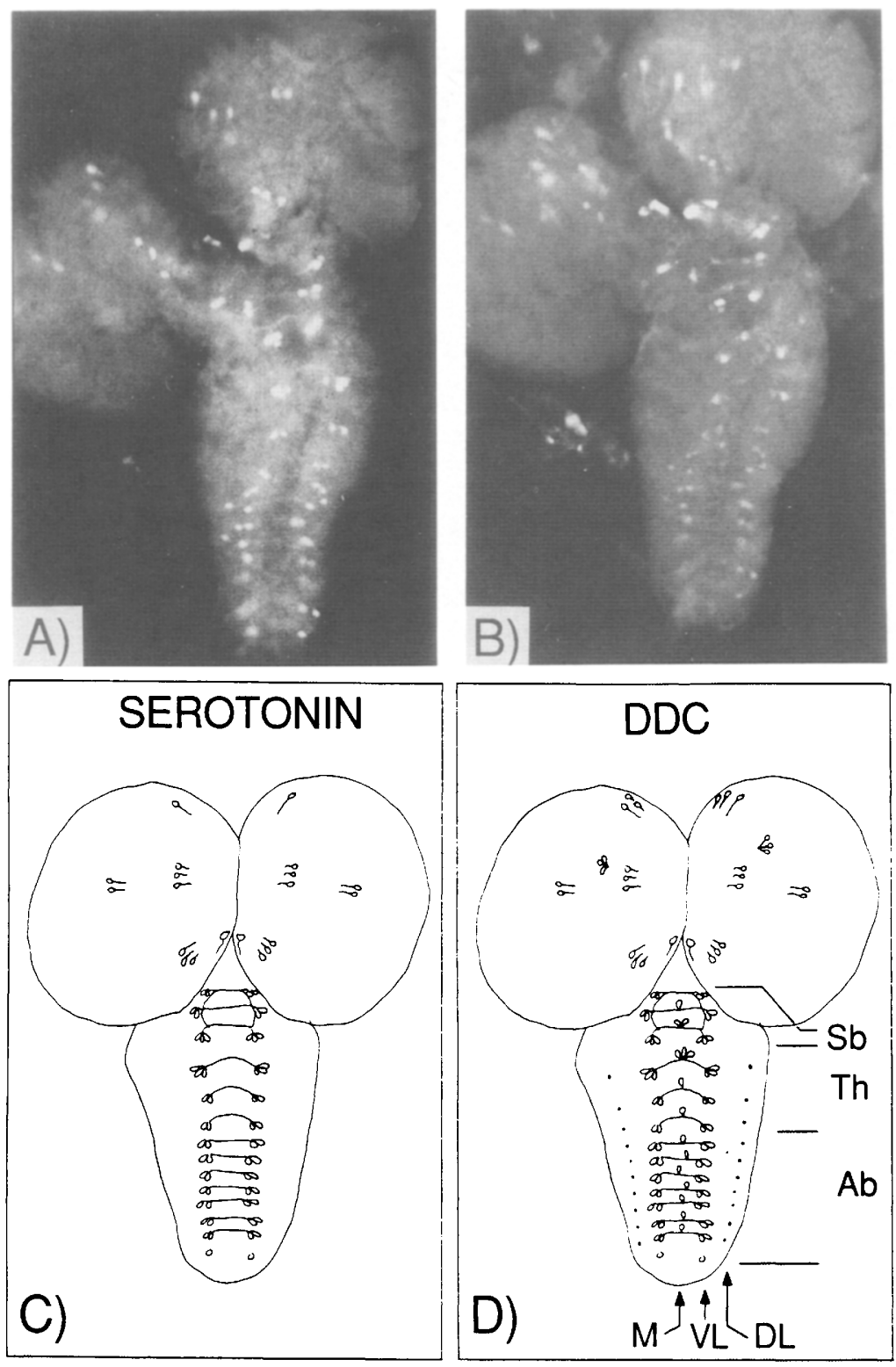

genes lacking this element express $D d c$ enzyme activity at high levels in the CNS in spite of marked abnormalities in cell-specific expression.

\section{Results}

Neuronal Ddc expression and comparison to monoamine neurotransmitter patterns in the larval CNS

We produced a $D d c$ antibody against a hybrid fusion protein synthesized in Escherichia coli. Staining the larval CNS with this antibody produces a robust pattern of about 125 cells distributed in a rather regular pattern in the segmented ventral ganglion and in clusters within the brain lobes (Fig. 1). The specificity of this antibody is demonstrated below, in that mutant strains synthesizing low levels of CNS Ddc activity do not stain detectably (Fig. 5C).
Figure 1. Staining of the larval CNS with antibodies to serotonin $|A|$ and $D d c(B \mid$, and schematic representations of the staining patterns $(C, D) .(A, C)$ Serotonin immunoreactive cell bodies are present in both the brain lobes and in the segmented ventral ganglion (White and Vallés 1985; Vallés and White 1986). They are located in ventral-lateral positions (VL) in the ganglion, with most segments showing two close pairs of cells that are connected by a bundle of fibers that also stains positive for serotonin. This pattern is present in 11 of the $14 \mathrm{seg}$ mental units. The eighth abdominal (Ab) segment contains two single serotonin cells and no detectable fiber connecting them, whereas the third subesophogeal $(\mathrm{Sb})$ and first thoracic (Th) segments contain triplets of serotonin cells. The assignment of serotonin neurons to segments has been displaced by one from that given by Vallés and White (1986), which assumed two head and nine abdominal segments, since the top three segmental units of serotonin cells stay with the subesophogeal ganglion when it separates from the rest of the ventral ganglion at metamorphosis (A.M. Vallés, pers. comm.). The brain lobes each have four groups of cells that stain positively for serotonin, located anterodorsally, mediodorsally, mediolaterally, and posteroventrally. $(B, D) D d c$ cells. All serotonin cells stain with the anti-Ddc serum. The ganglion $D d c$ cells that do not contain serotonin are located in a medial (M) row, and two dorsal-lateral (DL) rows. There is one cell per segment in these rows, except for the first thoracic segment, which contains three medial cells, the third subesophogeal segment, which contains two medial cells, and the eighth abdominal and first subesophogeal segment, which do not contain any medial cells. There are also two groups of cells in each brain lobe that label with the anti- $D d c$ antibody but are not serotonergic. These consist of two cells located at the anterior edge of each lobe and three cells located near the center of each lobe. There are variations in the relative intensity of cell staining seen with the $D d c$ and serotonin antibodies. In the thoracic and subesophogeal regions, one cell of each pair or triplet stains more intensely with the anti-Ddc antibody than the others in the set. Two of each pair or triplet stain intensely for serotonin, whereas one of the triplet cells stains less intensely for serotonin.

The pattern of $D d c$ staining in the wild-type larval CNS can be compared with the pattern observed when the tissue is stained concurrently with an antibody to serotonin (Fig. 1). All of the serotonin cells also stain with the anti- $D d c$ antibody, though additional cells stain positive for $D d c$. Budnik et al. (1986) have identified catecholamine-containing cells in the larval CNS by staining with glyoxylic acid. Glyoxylic acid stains dorsal-lateral and medial cells in the ventral ganglion that are located in positions apparently identical to those $D d c$-staining cells that do not contain serotonin. We assume that the cells that stain with both anti-Ddc antibody and glyoxylic acid contain dopamine. Three clusters of glyoxylic acid-staining cells were observed in the brain lobes, two of which correspond roughly to the 
two $D d c$-staining clusters that are not serotonergic. The third cluster of neurons that is detected by glyoxylic acid but not by $D d c$ staining may contain only L-dopa, which would not require $D d c$ for its synthesis, or its cells may contain low levels of $D d c$ activity not detectable at the sensitivity of this assay.

\section{Glial Ddc expression}

In addition to the staining of identifiable neuronal cell bodies and processes with the anti-Ddc antibody, we see staining of a network that is located primarily in the ventral cellular cortex of the ganglion (Fig. 2B) and near the medial surfaces of the brain lobes, both dorsally and ventrally (Fig. 2C). This staining is faint in wild-type CNS tissue and is not visualized easily in low-magnification photographs, such as that in Figure 1. This staining is on a subset of glial cells. Figure 2, C and D, shows a portion of a brain lobe from the CNS of a wildtype larva stained concurrently with the $D d c$ antibody and with a monoclonal antibody that stains glial cells in the CNS (N. Patel and C. Goodman, pers. comm.). Both antibodies stain a set of fibrous strands on the anteriomedial surface of the brain lobe and a structure associated with the developing optic lobe. Both antibodies also show staining in the cellular cortex of the larval ventral ganglion, with no detectable staining of the neuropil (data not shown). The antibodies must recognize distinct antigens, since the glial antibody shows more extensive staining than the $D d c$ antibody. The glial antibody stains the entire cellular cortex, whereas the $D d c$ antibody staining is restricted to the ventral and lateral cellular cortex. Even in the ventral cortex, however, the $D d c$ antibody stains only a subset of the pattern stained by the glial antibody.

\section{Localizing cell-specific Ddc promoter elements}

To determine the promoter requirements for cell-specific expression, we stained CNS tissue from strains containing $D d c$ genes with progressively truncated $5^{\prime}$ flanking sequences (Fig. 3A) (Hirsh et al. 1986). All of the mutant $D d c$ genes shown express at normal or abovenormal levels in the larval CNS, as assayed by enzyme activity measurements on tissue homogenates (Hirsh et al. 1986; unpubl.). Staining of representative larval CNSs from strains containing $D d c$ genes with 2500,800 , or 208 bp of normal 5 -flanking sequences is shown in Figure 4 , and the results of examining additional strains are summarized in Table 1 . The $D d c^{5 / \Delta \mid-2500)}$ genes are expressed normally: The wild-type neuronal pattern was seen in three out of four $D d c^{5 / \Delta(-2500)}$ strains examined (Fig. 4A; Table 1). Surprisingly, more severe truncations lead to a near-total loss of neuron-specific expression.
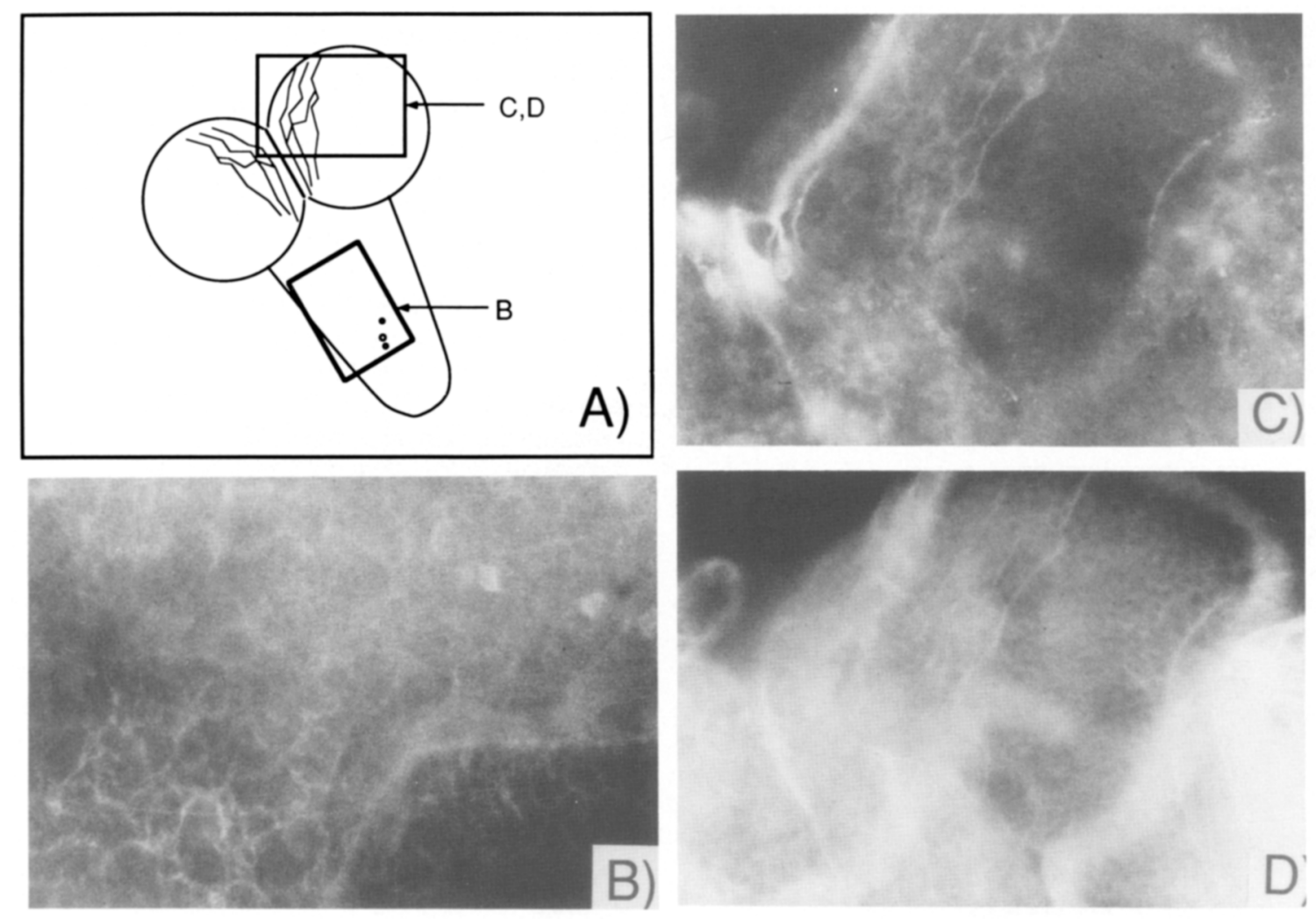

Figure 2. Glial expression of $D d c$ in a wild-type (Canton-S) larval CNS. (A) Diagram of the larval CNS, indicating regions enlarged in the micrographs. (B) $D d c$ staining of the ventral ganglion. The micrograph shows a ventral focal plane, with a diffuse network of staining in the cellular cortex and three medial cells at the right. $(C, D)$ A region of the brain lobe, double labeled with the $D d c$ antibody $(C)$ or with a glial antibody $(D)$. A common set of anteriomedially located fibers and a structure associated with the developing optic lobe (at the right of the figure) are stained by both antibodies. 


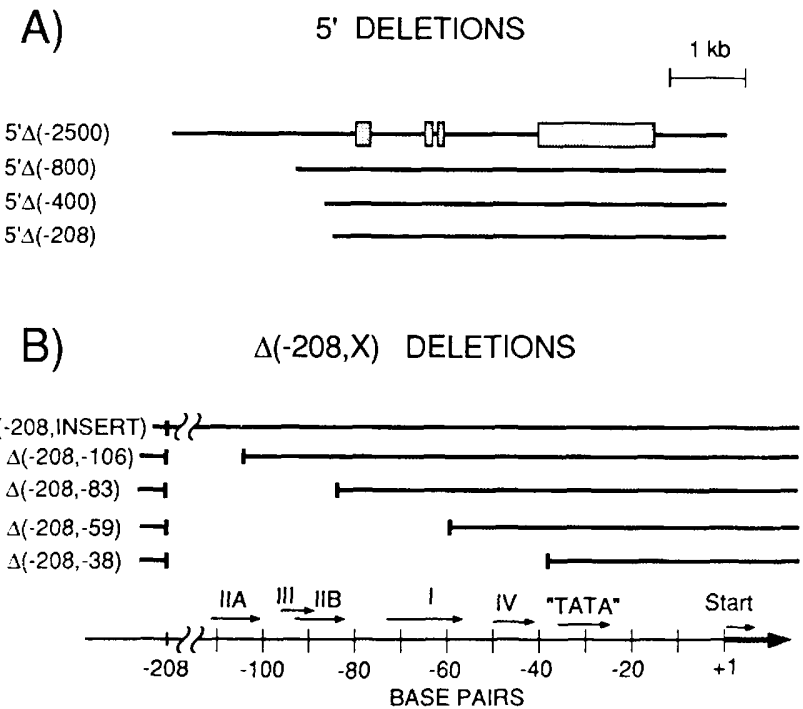

Figure 3. Mutant $D d c$ genes. $(A) 5^{\prime}$ deletions, as described in Hirsh et al. (1986). $(B) \Delta(-208, \mathrm{x})$ deletions, as described in Scholnick et al. (1986). The labeled arrows represent sequence elements conserved between the $D d c$ genes of $D$. melanogaster and $D$. virilis (Bray and Hirsh 1986). The $\Delta(-208, x)$ deletions retain $D d c$ sequences to -2200 and are deleted for sequences from -208 to the indicated end points. The $(-208$, Insert $)$ gene contains an insertion of one $\mathrm{BamHI}$ and two $\mathrm{XbaI}$ oligonucleotide linker sequences at -208 . All other genes contain one $\mathrm{BamHI}$ and one $\mathrm{XbaI}$ linker at the site of the deletion. The altered $D d c$ genes have been assayed previously for temporal and tissue-specific expression following germ line integration via $\mathrm{P}$ element vectors (Hirsh et al. 1986; Scholnick et al. 1986).

The $D d c^{5 / \Delta(-800)}, D d c^{5 \prime \Delta(-400)}$, and $D d c^{5 \prime \Delta(-208)}$ strains all show intense staining of the glia and, with only one exception (strain 24-44, Table 1), show no detectable staining of neuronal cell bodies. The intense staining of the glial network almost certainly accounts for the high levels of CNS Ddc enzyme activity in these strains.

We also examined larval CNS staining of strains containing a series of fine-structure deletions, which served to define a promoter element between -83 and -59 , necessary for $D d c$ expression in the CNS (Scholnick et al. 1986; Fig. 3B). These genes contain 5'-flanking sequences from $-2200 \mathrm{bp}$ to $-208 \mathrm{bp}$ and either have a 36 -bp linker sequence inserted at -208 (INSERT) or are deleted between this point and $-140,-106,-83,-59$, or $-35 \mathrm{bp}$. The staining patterns of two CNSs that are representative of the entire series of mutants are shown in Figure 5 and additional results are summarized in Table 1. A CNS from a $D d c^{\Delta(-208,-83)}$ larva shows neuron-specific and glial staining. The neuronal staining is visible mainly in the abdominal region of the ventral ganglion in the example shown (Fig. 5A,B), but all of the normally staining cells are visible at high magnification. The normal pattern of cell staining is visible in seven of nine strains that have end points upstream of -83 , whereas the other two strains show altered cellular patterns of staining (Table 1). In contrast, a CNS from a $D d c^{\Delta(-208,-59)}$ larva shows neither neuronal nor glial staining (Fig. 5C). This is also found in two other $D d c^{\Delta(-208,-59)}$ strains and one $D d c^{\Delta(-208,-35)}$ strain (Table 1).

Even though the $D d c^{\Delta(-208,-59)}$ strains show no detectable $D d c$ staining, staining for serotonin shows that they must express low levels of $D d c$ in the CNS (Fig. 5D). The serotonin in the $D d c^{\Delta(-208,-59)}$ CNS is not the result of serotonin diffusing into the CNS, since this does not occur in vivo (A-M. Vallés, pers. comm.; B. Morgan and J. Hirsh, in prep.). The intensity of cell staining is $10-30 \%$ of normal, comparable to the intensity observed in a $D d c^{t s 2}$ CNS, isolated from an animal grown at $25^{\circ} \mathrm{C}$ (White and Vallés, 1985; unpubl.). Under these conditions, the $D d c^{t s 2}$ larval CNS contains less than $5 \%$ of normal levels of $D d c$ activity (Scholnick et al. 1986) and shows no detectable $D d c$ staining.

\section{Variations in neuron-specific expression of Ddc}

We detect variations in intensity of neuron-specific staining between strains carrying the different $D d c \mathrm{mu}$ tations and some variation in the pattern of staining (Table 1). The strains carrying $D d c^{\Delta(-208,-x)}$ genes stain with an intensity $50-100 \%$ of normal for all deletions up to and including -83 , except for two $D d c^{\Delta(-208,-106)}$ strains which stain at about $20 \%$ of normal. There is, however, little variation in staining intensity between individual CNSs from a given strain.

Four strains showed $D d c$ expression in only a subset of the normal neurons in the ganglion (Table 1 ; Fig. 6). One of the $D d c^{5 / \Delta(-2500)}$ strains, 9-4A, showed normal staining of the medial, dorsal-lateral, and subesophogeal ventral-lateral cells, yet showed only very faint staining of the ventral-lateral cells (Fig. 6A,B). The remaining ventral-lateral cell staining is most intense in the subesophogeal region, as is the case for staining in wild-type strains. One $D d c^{5 / \Delta(-208)}$ strain, 24-44A, showed dorsallateral cell staining (not shown), whereas nine other $D d c^{5 / \Delta(-208)}$ strains showed no detectable neuronal staining. One $D d c^{\Delta(-208,-106)}$ strain, 65-1, showed staining only in the ventral-lateral cells (Fig. 6C). Finally, one $D d c^{\Delta(-208, \text { insert) }}$ strain, 56-3A, showed staining only in dorsal-lateral and subesophogeal ventral-lateral cells (Fig. 6D). This latter strain is unusual in that it is the only strain to show evidence for expression of $D d c$ in cells where expression is not normally observed. Close examination of the dorsal lateral cells (Fig. 6D) shows $D d c$ staining in doublets of cells, whereas this staining is normally in well-separated single cells (Fig. 6A). These variations in the cell-specific patterns and levels of $D d c$ expression must be due either to position effects or to alterations in the $D d c$ genes during the course of vector construction or insertion into the Drosophila germ line. We favor the former possibility, since none of the strains shows evidence for $D d c$ gene alterations when examined by whole genome blots (not shown). Only one of the insertions showing an aberrant pattern of expression is inserted into a chromosomal region that is clearly heterochromatic; the $D d c^{\Delta(-208,-106)}$ strain $65-1 \mathrm{~A}$ is inserted into centric heterochromatin. 

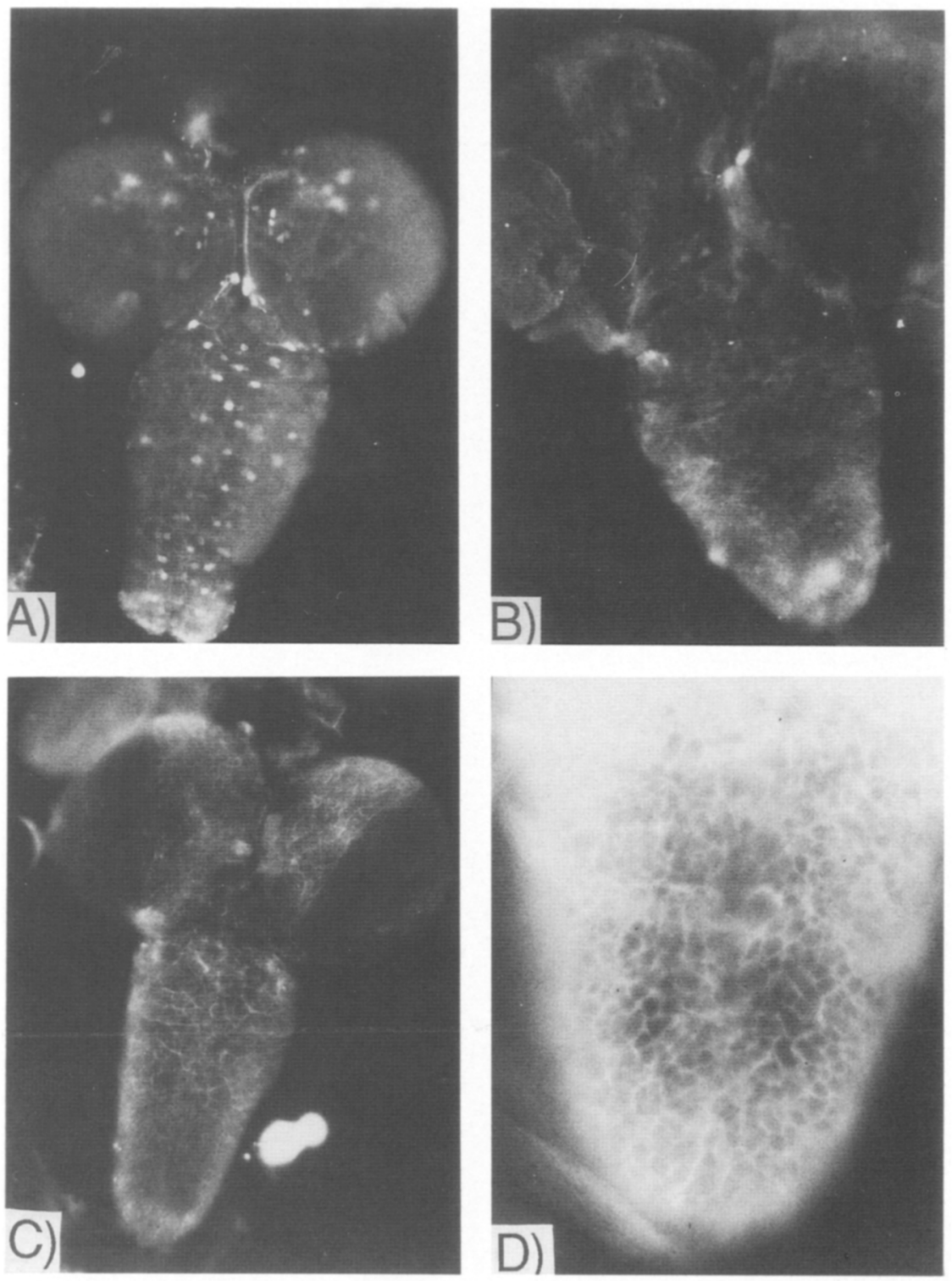

Figure 4. Cell-specific expression of mutant $D d c$ genes in the larval CNS. Strain numbers and the $D d c$ genes that they contain: $(A)$

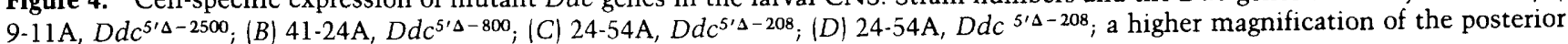
abdominal region, ventral focal plane. All of the mutant genes were in a $D d c^{t s 2}$ background.

\section{Discussion}

Regulatory elements for expression of Ddc in the CNS

The interaction of at least two cis-regulatory elements is required to generate the normal cellular pattern of $D d c$ gene expression in the larval CNS (Fig. 7). One of these elements, element $I$, is located at about -60 bp relative to the RNA start point and previously has been shown to be required for normal levels of $D d c$ expression in both the larval CNS and adult brain (Scholnick et al. 1986). The second element is defined less precisely and presently is located between deletion end points at -800 and $-2200 \mathrm{bp}$, a region large enough to contain multiple regulatory sites. When both elements are present, $D d c$ is expressed in about 125 neurons and in a network con- sisting of a subset of glial cells. Neither element alone is sufficient to generate the normal pattern of $D d c$ gene expression. When the distal element is deleted, neuronal $D d c$ expression is not observed, even though overall CNS $D d c$ enzyme activity is at normal or above-normal levels (Hirsh et al. 1986). The Ddc activity in these strains is located predominantly in glial cells, where it is overexpressed relative to wild type. When the proximally located element I is deleted, $D d c$ expression is reduced to levels undetectable by $D d c$ immunohistochemistry or by whole CNS Ddc enzyme assays (Scholnick et al. 1986).

These results suggest a simple model for the generation of the specific pattern of neuron-specific $D d c$ expression. Both CNS regulatory elements must be present 
Table 1. Ddc staining of wild-type and mutant larval CNS

\begin{tabular}{|c|c|c|c|c|}
\hline$D d c$ gene & Strain (cytologic location) $)^{a}$ & Cell body intensity ${ }^{b}$ & Cell pattern ${ }^{c}$ & Glial stainingd \\
\hline Wild type & Canton $\mathrm{S}$ & 3 & + & + \\
\hline \multirow[t]{4}{*}{$5^{\prime} \Delta(-2500)$} & DR $4[90 E-F]$ & 3 & + & + \\
\hline & $9-11 \mathrm{~A}$ & 3 & + & + \\
\hline & $13-1 \mathrm{~A}$ & 2 & + & ++ \\
\hline & $9-4 \mathrm{~A}[57 \mathrm{~A}]$ & $3(1)$ & $+(\mathrm{VL})$ & + \\
\hline \multirow[t]{2}{*}{$5^{\prime} \Delta(-800)$} & $19-8 \mathrm{~A}$ & 0 & - & ++ \\
\hline & $41-24 \mathrm{~A}$ & 0 & - & ++ \\
\hline \multirow{2}{*}{$5^{\prime} \Delta(-400)$} & $14-4 \mathrm{~A}$ & 0 & - & $t+$ \\
\hline & $14-16 \mathrm{~A}$ & 0 & - & ++ \\
\hline \multirow[t]{2}{*}{$5^{\prime} \Delta(-208)$} & $24-44 \mathrm{~A}[99 \mathrm{~A}-\mathrm{B}]$ & 3 & DL only & ++ \\
\hline & (nine others) & 0 & - & $+t$ \\
\hline \multirow[t]{2}{*}{$\Delta(-208$, insert $)$} & $56-3 \mathrm{~A}[37 \mathrm{~A}]$ & $2(1)$ & $\mathrm{DL}^{\star}(\mathrm{VL})$ & ++ \\
\hline & $56-7 \mathrm{~A}[46 \mathrm{D}]$ & 2 & + & ++ \\
\hline \multirow[t]{2}{*}{$\Delta(-208,-140)$} & $57-12 \mathrm{~A}[26 \mathrm{C}-\mathrm{F}]$ & 2 & + & ++ \\
\hline & $57-29 \mathrm{~A}$ & 3 & + & ++ \\
\hline \multirow[t]{3}{*}{$\Delta(-208,-106)$} & 65-1A [X heterochromatin] & 1 & VL only & ++ \\
\hline & $65-13 \mathrm{~A}[75 \mathrm{C}]$ & 1 & + & ++ \\
\hline & $65-16 \mathrm{C}[89 \mathrm{~B}]$ & 2 & + & ++ \\
\hline \multirow[t]{2}{*}{$\Delta(-208,-83)$} & $60-3 A[95 D-E]$ & 2 & + & ++ \\
\hline & $60-15 \mathrm{~A}[52 \mathrm{C}-\mathrm{D}]$ & 3 & + & ++ \\
\hline \multirow[t]{3}{*}{$\Delta(-208,-59)$} & $63-10 \mathrm{C}$ [two inserts: $22 \mathrm{AB}, 31]$ & 0 & - & - \\
\hline & $63-19 \mathrm{~B}[25 \mathrm{~F}-26 \mathrm{~A}]$ & 0 & - & - \\
\hline & $63-39 \mathrm{~A}[21 \mathrm{~B}-\mathrm{C}]$ & 0 & - & - \\
\hline$\Delta(-208,-38)$ & $61-25 \mathrm{~A}[77 \mathrm{~B}-\mathrm{D}]$ & 0 & - & - \\
\hline
\end{tabular}

a Where determined.

b (0) No staining detectable; (1) faint, 10-20\% of normal; (2) roughly half-normal intensity; (3) near-normal intensity.

c Classes of cells in the ventral ganglion are as indicated in Fig. l. (VL) Ventral lateral; (DL) dorsal lateral; (VM) ventral medial; (DL $\left.{ }^{*}\right)$ dorsal-lateral-appearing cells that are often doublets. We have not attempted to describe the pattern of expression in the brain lobes, since it is harder to discriminate unambiguously between the different $D d c$-containing neuronal clusters

d $|-|$ Not detectable; $|+|$ normal; $|++|$ above normal.

for cell-specific neuronal expression. Presumably, each must be bound by appropriate activator proteins. In principle, each of these regulatory proteins could be present in the same cellular pattern in the CNS. A more attractive and economical possibility is that each regulatory protein could be expressed in a different pattern of cells in the CNS, with Ddc expression occurring only in the intersecting subset of cells that contain both regulatory proteins. This would allow the generation of different patterns of cell-specific gene expression by varying only one of the two elements. A similar model has been proposed to account for the novel neural expression of a metallothionein-growth hormone fusion gene (Swanson et al. 1985). Neither parental gene is expressed in neural cells, yet a hybrid gene composed of the metallothionein promoter-regulatory region fused to the body of the growth hormone gene is expressed in a small subset of neural cells. Analogous examples of inappropriate temporal or tissue-specific expression of hybrid genes have now been observed in at least two other instances (Simon et al. 1985; Shermoen et al. 1987).

One prediction of this model is that it would be expected that other genes sharing common cellular or tissue-specific regulation with $D d c$ would contain similar regulatory elements. In support of this prediction, an oligonucleotide probe containing element I sequences detects numerous sequences complementary to element I within the Drosophila genome (S.J. Bray, unpubl.).
However, the regulatory functions of these sequences remain to be determined. This probe does not show any detectable hybridization within the region encompassing the distal CNS element, making it unlikely that this region contains a second copy of element $\mathrm{I}$.

This regulatory model clearly does not pertain to $D d c$ expression within the glial cells, since deletions of the region encompassing the distal CNS element result in overexpression of $D d c$ in glial cells. These results could be explained if the distal region contained a repressor of glial cell expression in addition to a CNS activator element.

The $D d c$ regulatory elements could be shared with adjacent transcription units. $D d c$ is within a dense cluster of genes and transcripts (reviewed in Wright 1987), with one transcript terminating at about $-1500 \mathrm{bp}$ relative to $D d c$ (Fig. 7; Eveleth et al. 1986). The overlap of this transcript with the region defining the $D d c$ distal CNS element leads to the suspicion that this element might effect regulation of this transcript as well. Not enough is known at present regarding the regulation of this upstream transcription unit to confirm this association.

Inferences from strains showing exceptional patterns of cell-specific Ddc expression

Of the 31 strains examined that contain $D d c$ genes within P-element vectors, all but four show patterns of 

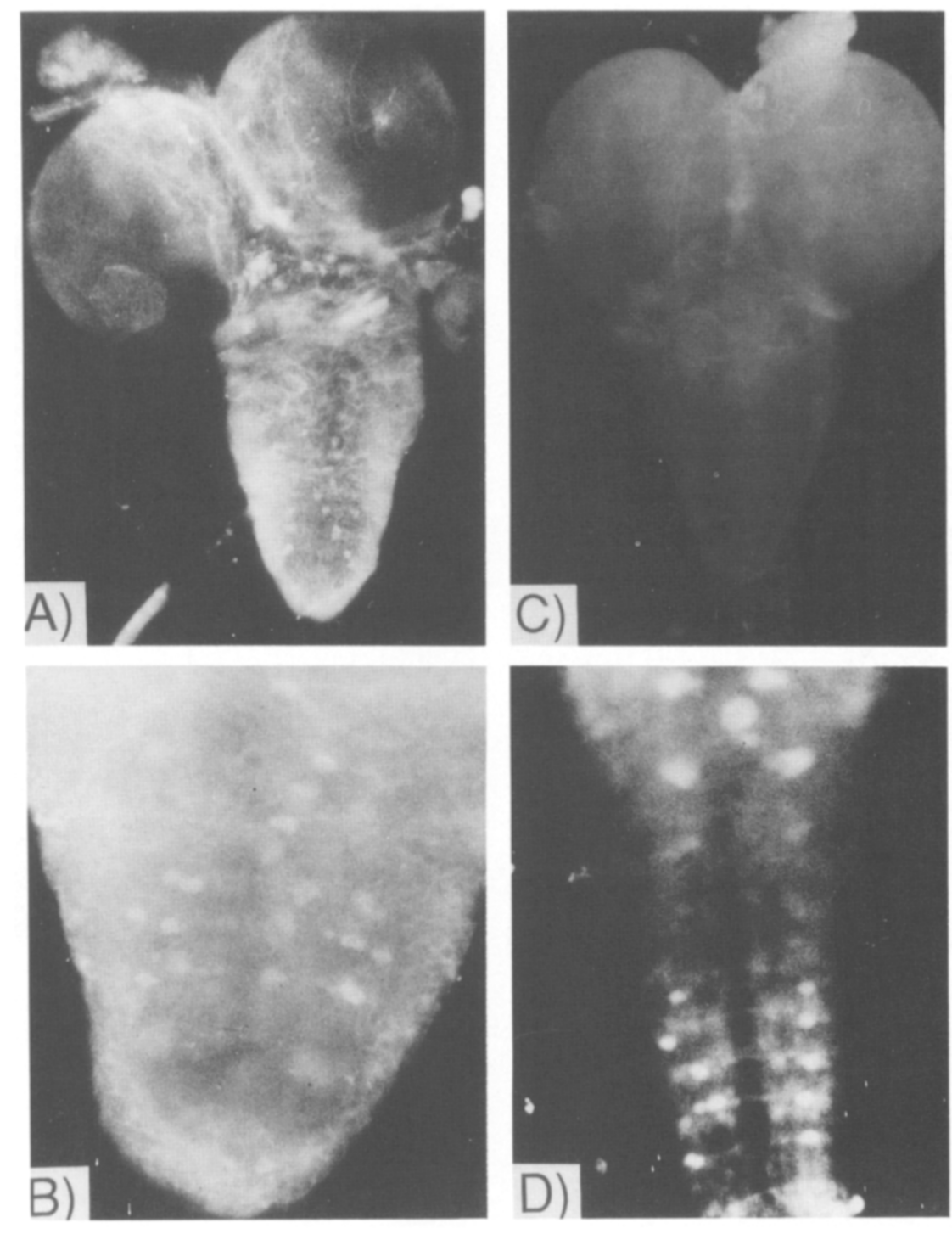

Figure 5. Cell-specific larval CNS expression of $D d c$ mutants with deletion end points flanking CNS expression element I. $|A-C|$ Stained with the $D d c$ antibody; $(D \mid$ stained with the serotonin antibody. Strain numbers and the $D d c$ genes that they contain: $|A|$ 60-15A, $D d c^{\Delta(-208,-83)} ;(B)$ A higher-magnification view of the posterior abdominal region of the $D d c^{\Delta(-208,-83)}$; ventral ganglion. $(C)$ 63-19A, Ddc $c^{\Delta(-208,-59)}$. The genetic background in $A-C$ is $D d c^{t s 2}$. (D) Larval CNS of strain 63-39A, Ddc $c^{\Delta(-208,-59)}$ stained with a serotonin antibody. This strain was in a $D d c$ deficiency background, since the $D d c^{\text {ts } 2}$ genes lead to the synthesis of significant amounts of serotonin even when grown at restrictive temperatures (White and Vallés 1985; unpubl.). The hazy background is neuropil staining which, at higher magnification, has a punctate appearance (not shown). The medial spot near the top of the photograph is a staining artifact.

$D d c$ expression common to sibling strains containing apparently identical genes. The expression of these exceptional strains must be altered either by the effects of adjacent chromosomal sequences or by mutational alterations within the $D d c$ genes. We consider chromosomal position effects to be the most likely explanation, since none of these genes shows detectable alterations by whole genome blot analysis (data not shown). Chromosomal position effects have been shown previously to alter the expression of P-element transposed genes in complex tissue-specific and spatially dependent manners (Hazelrigg et al. 1984; Simon et al. 1985; Glaser et al. 1986; J.T. Lis, pers. commun.). Only one of these exceptional $D d c$ strains, strain $65-1 \mathrm{~A}$, contains an insert into centric heterochromatin (Table 1). Proximity to heterochromatin often makes adjacent genes sensitive to position effects (Spofford 1976).

The altered patterns of expression give clues regarding the cell-specific regulatory elements retained within these genes. Two of the exceptional strains show a gain of function relative to sibling strains containing identical Ddc genes (Table 1). One of these, strain 24-44 $D d c^{5 / \Delta(-208)}$, shows expression in the dorsal-lateral cells, whereas none of the other nine sibling strains shows detectable expression in any neuronal cells. The most probable conclusion from this result is that the $D d c^{5 / \Delta(-208)}$ genes retain a regulatory element partially sufficient for expression in dorsal-lateral cells. It seems 

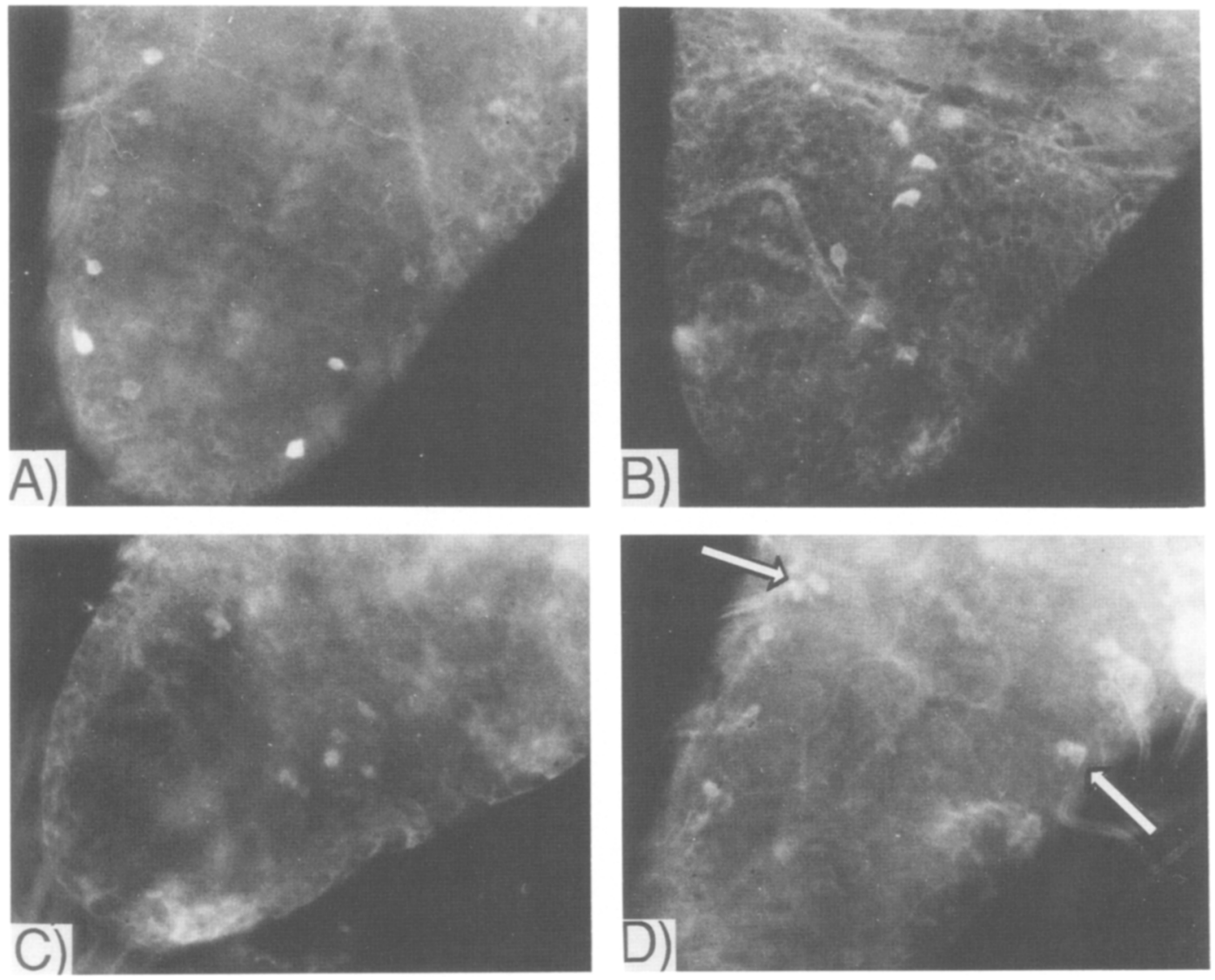

Figure 6. Strains showing alterations in the normal pattern of $D d c$ cell-specific expression. Strain numbers and the $D d c$ genes that

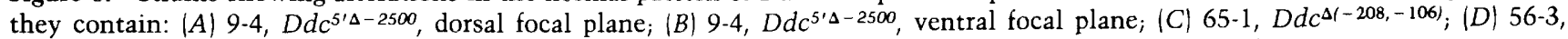
$D d c^{\Delta(-208,- \text { insert })}$, dorsal focal plane. Note the dorsal-lateral cells, marked by arrows, which appear as doublets.
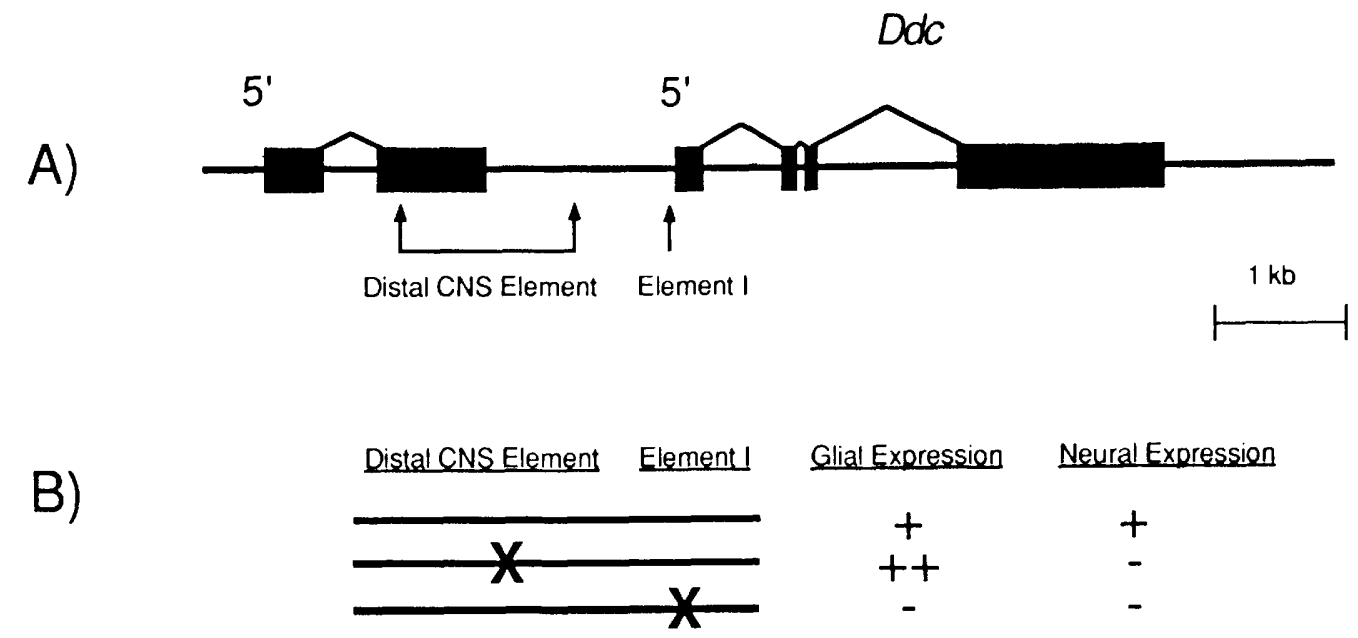

Figure 7. (A) Summary of positions of the Ddc CNS regulatory elements. The distal CNS element is located between -800 and $-2200 \mathrm{bp}$, relative to the Ddc RNA start point, whereas element I is located at -57 (Bray and Hirsh 1986; Scholnick et al. 1986). Exons of $D d c$ (Morgan et al. 1986) and of an adjacent transcription unit (Eveleth et al. 1986) are shown as black boxes, with arching lines indicating intervening sequences. The position of this latter transcript on the DNA map has been determined by comparing restriction sites in the cDNA sequence given by Eveleth et al. (1986), with our restriction site mapping data. This transcription unit terminates $1500 \mathrm{bp}$ upstream from $D d c$. $(B)$ Summary of the effects of deleting either element on glial or neuronal expression. $(\times)$ Deletion of the element. Levels of expression are given as follows: $\{-\mid$ no expression immunohistochemically detectable; $|+|$ wildtype levels; $1++\mid$ greater than wild-type levels. 
much less likely that this integration site is adjacent to a regulatory element sufficient to account for this expression. The other strain showing a gain of function is strain 56-3A $\left[D d c^{\Delta /-208,}\right.$ insert $\left.)\right]$, which shows expression in cells that are in the positions expected for dorsal-lateral cells, except that many appear as doublets instead of the single cells normally observed. Since our identification of cell type is based only on morphological and spatial criteria, it is possible that both cells of the doublets are novel cells different from the dorsal-lateral cells in which $D d c$ is normally expressed.

Two of these exceptional strains show a selective loss of expression in subsets of the expected cells. Strain 9-4 $\left(D d c^{5 / \Delta-2500}\right)$ shows a loss of expression in the ventrallateral (serotonergic) cells while retaining apparently normal expression in the medial and dorsal-lateral cells, both of which are dopaminergic. Strain 65-1 $\left[D d c^{\Delta(-208,-106)}\right]$ shows a reciprocal phenotype, with loss of expression in the medial and dorsal-lateral cells while retaining apparently normal expression in the serotonergic ventral-lateral cells. These results imply separable $D d c$ regulatory elements, at least for the dopaminergic and the serotonergic cells of the ventral ganglion. The observation that strain 24-44 $\left(D d c^{5 / \Delta-208}\right)$ shows expression in the dopaminergic dorsal-lateral cells, without expression in the dopaminergic medial cells, implies that further cell class-specific elements may exist as well.

\section{Glial expression of Ddc}

Subsets of glial cells from vertebrates have been shown to contain serotonin and dopamine and to take up these compounds in vitro (Henn and Hamberger 1971; reviewed in Liesi et al. 1981). However, we know of no other instance where biosynthetic enzymes for serotonin or dopamine have been found in glial cells. The finding of $D d c$ enzyme in Drosophila glial cells was unexpected, since the glial network does not stain positive for either serotonin (White and Vallés 1985; data not shown) or catecholamines (Budnick and White 1986). It is possible, however, that the glia contain low levels of biogenic amines below the level of histochemical detection.

\section{Concluding remarks}

The results reported in this communication show complexity in the regulation of cell-specific expression of $D d c$ in the CNS. Further studies should yield a more precise mechanism by which $D d c$ expression is controlled at the cellular level. This could provide the means to alter the expression of $D d c$ and other genes in specific cells within the CNS and enable a better definition of the physiologic roles of $D d c$ expression in the CNS.

\section{Materials and methods}

Drosophila strains used

Three in vivo-generated $D d c$ mutant chromosomes were used. $D f(2 L) 130$ is a cytologically visible deletion that removes the
$D d c$ gene entirely (Wright et al. 1976). $D d c^{\text {n27 }}$ is a small deletion that removes the first two $5^{\prime}$ exons of the gene (Gilbert et al. 1984). $D d c^{t s 2}$ is a temperature-sensitive mutation of the gene (Wright et al. 1982). The construction of most of the strains containing transduced, in vitro-generated mutant $D d c$ genes has been described Scholnick et al. 1983, Hirsh et al. 1986). The $D d c^{5 / \Delta}(-800)$ strains contained a $5.4-\mathrm{kb}$ Pst-HindIII fragment encompassing $D d c$. Two $D d c^{5 / \Delta(-800)}$ strains were used: Each contains the $5.4-\mathrm{kb}$ fragment inserted in a P element along with a fragment of the alcohol dehydrogenase $(A d h)$ gene, with the 3 ' end of each gene directed toward the center of the transposon. Strain 19-8 contains a 4.9-kb EcoRI fragment of the Adh gene, whereas the 41-24 strain contains a truncated Adh fragment that extends from the EcoRI site 3' to a Sau3a site, $40 \mathrm{bp} \mathrm{5'}$ of the proximal $A d h$ promoter. All strains containing in vitro-altered $D d c$ genes were homozygous for the inserted genes.

Cytological locations of the integrated genes were determined by in situ hybridization to salivary polytene chromosomes, as described previously (Hirsh and Davidson 1981).

\section{Production of anti-Ddc antibody}

A BamHI-PstI fragment of the Ddc gene was cloned into the open reading frame expression vector pEX 3 (Stanley and Luzio 1984), cut with the same two enzymes. The resulting plasmid, designated pDORF 401, coded for a fusion polypeptide containing, sequentially from the amino terminus, portions of the phage $\lambda$ Cro protein, the E. coli lac repressor protein, the E. coli $\beta$-galactosidase protein, and the carboxy-terminal 175 amino acids of dopa decarboxylase. The synthesis of the protein is under the control of the $P_{\mathrm{R}}$ promoter in a strain with a temperature-sensitive $\lambda$ repressor (strain SY 638). Synthesis of the fusion protein was induced by shifting the cells containing the plasmid from $30^{\circ} \mathrm{C}$ to $42^{\circ} \mathrm{C}$ for $1 \mathrm{hr}$, after they had reached an optical density of 0.1 at $600 \mathrm{~nm}$. The fusion protein was purified by its insolubility as follows. Induced culture $(50 \mathrm{ml})$ was spun down and resuspended in $0.2 \mathrm{ml}$ of $20 \%$ (wt/vol) sucrose, $0.05 \mathrm{M}$ Tris $(\mathrm{pH} 7.5) ; 40 \mu \mathrm{l}$ of $10 \mathrm{mg} / \mathrm{ml}$ lysozyme was added and the cells were left on ice for $5 \mathrm{~min} ; 40 \mathrm{ml}$ of $0.5 \mathrm{M}$ EDTA was added and left an additional $5 \mathrm{~min}$ on ice; $0.33 \mathrm{ml}$ of $50 \mathrm{~mm}$ Tris (pH 7.5), $10 \mathrm{~mm}$ EDTA, and $0.1 \%$ (vol/vol) Triton X-100 were then added and left for $15 \mathrm{~min}$ on ice. After this time, the sample was spun for $15 \mathrm{~min}$ in a microfuge. Most of the cell proteins were present in the supernatant, whereas most of the fusion protein was present in the pellet. The pellet was extracted with $0.4 \mathrm{ml}$ of $5 \mathrm{M}$ urea to remove residual cell proteins, and the fusion protein was solubilized in $0.4 \mathrm{ml}$ of $8 \mathrm{M}$ urea. The yield of protein was about $75 \mu \mathrm{g}$, as measured by a Bradford protein assay (Bio-Rad).

One-quarter of the purified material was dialyzed against phosphate-buffered saline (PBS) $\left(0.9 \% \mathrm{NaCl}, 10 \mathrm{mM} \mathrm{NaPO}_{4}, \mathrm{pH}\right.$ 7.5) overnight, emulsified with Freund's complete adjuvant (Sigma), and injected subcutaneously in the neck region of a New Zealand white rabbit. The initial injection was followed 2 weeks later by a boost injection of the same amount of antigen, emulsified in Freund's incomplete adjuvant. The rabbit was bled at 1, 10, and 14 weeks following the boost, and antibody production was monitored by a Western blot assay (see below). A reactive antiserum was derived from the 10 -week bleed.

The 10-week antiserum was affinity-purified for specificity to the $D d c$ protein sequences. Large preparations of the pDORF 401 fusion protein and the starting protein from pEX 3 were produced by directly scaling up the procedure given above. Purified protein from $500 \mathrm{ml}$ of each culture was coupled to $1 \mathrm{ml}$ of Affi-Gel 10 beads (Bio-Rad), according to the procedure of the manufacturer. The original antiserum was purified by two 
batch incubations with the pEX 3-coupled beads to remove antibodies to $\beta$-galactosidase and other $E$. coli proteins. The antiserum was incubated with the pEX resin for $3 \mathrm{hr}$, after which the resin was removed, treated with low $\mathrm{pH}$ (see below) to remove bound antibodies, and mixed again with the serum for 3 hr. The $D d c$ specific antibodies were bound to the pDORF 401 column in one pass. The column was washed thoroughly with PBS, and the bound antibody was eluted by low $\mathrm{pH}$, either with $0.1 \mathrm{~m}$ glycine $(\mathrm{pH} 2.0), 100 \mu \mathrm{g} / \mathrm{ml}$ bovine serum albumin (BSA), or with $0.15 \mathrm{M} \mathrm{NaCl}, 0.5 \%$ (vol/vol) glacial acetic acid. The eluate was neutralized by the addition of $1 \mathrm{M}$ Tris $(\mathrm{pH} 9)$ and diluted in PBS. Fifteen milliliters of starting serum was eluted in a final volume of $3 \mathrm{ml}$.

\section{Specificity of the Ddc antiserum}

The best preparations of affinity-purified antiserum showed no staining of a $\mathrm{Ddc}^{-}$larval CNS, as shown in Figure 5C. Antibody preparations with lower titers of $D d c$ specificities occasionally showed weak staining of about 10 cells and a set of four longitudinal strands on the dorsal surface of the ventral ganglion of a $D d c^{-}$CNS. This staining is due to a contaminating specificity, since this pattern of staining is shown by antibodies affinity-purified against the pEX protein.

\section{Whole-mount immunodetection of Ddc enzyme}

CNSs were dissected from late third-instar larvae that had been grown at $25^{\circ} \mathrm{C}$ in a normal stock vial. The pattern of $D d c$ staining in the wild-type CNS was invariant as a function of age from early first instars through prepupae (data not shown). Larval CNSs were incubated in $150-\mu l$ wells in a Plexiglass plate on a gyrotary shaker (New Brunswick Scientific), with all incubations at room temperature. The tissues were fixed in $4 \%$ formaldehyde (paraformaldehyde, depolymerized; Polysciences) for $30 \mathrm{~min}$, and washed three times for $5 \mathrm{~min}$ each in PBS. They were then washed twice for 5 min each in PBT [PBS with $0.1 \%$ (wt/vol) bovine serum albumin (BSA) and $0.1 \%$ (vol/vol) Triton $\mathrm{X}$-100). The $1^{\circ}$ antibody $(1: 20$ in PBT $)$ was allowed to bind to the tissues $8-12 \mathrm{hr}$. The material was washed five times for 5 min each with PBT. The $2^{\circ}$ antibody (affinity-purified fluorescein-conjugated goat anti-rabbit IgG from Cooper Biomedical, $1: 50$ in PBT) was applied for $8-12 \mathrm{hr}$ at room temperature. The secondary antibody was removed, followed by four washes for $5 \mathrm{~min}$ each in PBT, followed by a final wash for $2-10 \mathrm{hr}$. The tissue was mounted in $90 \%$ glycerol, $1 \mathrm{mg} / \mathrm{ml}$ phenylene diamine (tetrahydrochloride), and $2 \mathrm{~mm}$ sodium carbonate $(\mathrm{pH}$ 9) and examined on a Zeiss Standard microscope equipped with epifluorescence optics. In all cases, at least 10 larval CNSs were examined.

The $D d c$-serotonin double-label experiments were carried out by a similar procedure, except that the $1^{\circ}$ antibody was a mix of rabbit anti-Ddc and a rat anti-serotonin monoclonal antibody (Accurate Chemical Co.) diluted $1: 200$, and the $2^{\circ}$ antibody was a mix of rhodamine-labeled goat anti-rat (Cooper Biomedicall diluted 1:50 and fluorescein-labeled goat anti-rabbit, which had been passed three times over a rat IgG-Sepharose column (Cooper) in PBS to remove cross-reactive material. Control experiments (not shown), using the either primary antibody alone or with the heterologous secondary antibody, showed that the staining of the common neurons was not due to cross-reactivity of the secondary antibodies.

The glial staining was with a mouse monoclonal antibody (1B7), provided by Nipam Patel and Corey Goodman. This antibody detects glial cells in the embryonic CNS and in neuroblast cultures (N. Patel and C. Goodman, unpubl.), as determined by optical and electron microscopic immunocytochemistry. The specificity and staining pattern of the glial antibody is similar to that of several cricket glial antibodies isolated by Meyer et al. (1987).

The rough quantitation of fluoresence intensity shown in Table 1 was performed by visual estimation relative to wildtype standards included in every experiment. The quantitations were performed independently by both investigators, with full agreement on results.

The host strains used for immunodetection of Ddc in the larval CNS contained the chromosomal $D d c^{t s 2}$ alleles. The $D d c^{t s 2}$ strain shows no detectable CNS staining for $D d c$ when grown at $25^{\circ} \mathrm{C}$.

\section{Acknowledgments}

We wish to thank the investigators who shared their expertise and materials in teaching us immunocytochemical techniques: Barbara Beltz, Ursula Drager, Ana Maria Vallés, and Kalpana White. We thank Corey Goodman and Nipam Patel for generously providing the glial antibody. We thank Ian Hope for assistance in synthesis of the fusion protein and in production of the antisera. Bruce Morgan, Sarah J. Bray, and Wayne Johnson provided constructive comments on the manuscript. This work was supported by the National Institutes of Health (grant R01 GM 27318/ to J.H.

\section{References}

Bloom, F.E., E. Battenberg, A. Ferron, J.R. Mancillas, R.J. Milner, G. Siggins, and J.G. Sutcliffe. 1985. Neuropeptides: Interactions and diversities. Recent Prog. Horm. Res. 41: 339-367.

Bray, S.J. and J. Hirsh. 1986. The Drosophila virilis dopa decarboxylase gene is developmentally regulated when integrated into Drosophila melanogaster. EMBO J. 5: 2305-2311.

Budnik, V., L. Martin-Morris, and K. White. 1986. Perturbed pattern of catecholamine-containing neurons in mutant Drosophila deficient in the enzyme dopa decarboxylase. I. Neurosci. 6: 3682-3691.

Eveleth, D.D. and J.L. Marsh. 1986. Sequence and expression of the $\mathrm{Cc}$ gene, a member of the dopa decarboxylase gene cluster of Drosophila: Possible translational regulation. $\mathrm{Nu}$ cleic Acids Res. 14: 6169-6183.

Gilbert, D., J. Hirsh, and T.R.F. Wright. 1984. Molecular characterization of a gene cluster flanking the Drosophila dopa decarboxylase gene. Genetics 106: 679-694.

Glaser, R.L., M.F. Wolfner, and J.T. Lis. 1986. Spatial and temporal pattern of $h s p 26$ expression during normal development. $E M B O$ I. 5: 747-754.

Hazelrigg, T., R. Levis, and G.M. Rubin. 1984. Transformation of white locus DNA in Drosophila: Dosage compensation, zeste interaction, and position effects. Cell 36: 469-481.

Henn, F.A. and A. Hamberger. 1971. Glial cell functions: Uptake of transmitter substances. Proc. Natl. Acad. Sci 68: $2686-2990$.

Hirsh, J. and N. Davidson. 1981. Isolation and characterization of the Drosophila dopa decarboxylase gene. Mol. Cell. Biol. 1: 475-485.

Hirsh, J., B. Morgan, and S. Scholnick. 1986. Delimiting regulatory sequences of the Drosophila melanogaster Ddc gene. Mol. Cell. Biol. 6: 4548-4557.

Liesi, P., A. Paetau, L. Rechardt, and D. Dahl. 1981. Glial uptake of monoamines in primary cultures of rat median raphe nucleus and cerebellum. A combined monoamine fluorescence and glial fibrially acidic protein immunofluorescence study. Histochemistry 73: 239-250. 
Livingstone, M.S. and B.L. Tempel. 1983. Genetic dissection of monoamine neurotransmitter synthesis in Drosophila. $\mathrm{Na}$ ture 303: $67-70$.

Meyer, M.R., G.R. Reddy, and J.S. Edwards. 1987. Immunological probes reveal spatial and developmental diversity in insect neuroglia. J. Neurosci. 7: 512-521.

Morgan, B., W.A. Johnson, and J. Hirsh. 1986. Regulated splicing produces different forms of dopa decarboxylase in the central nervous system and hypoderm of Drosophila melanogaster. EMBO I. 5: 3335-3342.

Rosenfeld, M.G., S.G. Amara, and R. M. Evans. 1984. Alternative RNA processing: Determining neuronal phenotype. Science 225: 1315-1320.

Scheller, R.H., R.-R. Kaladny, T. Kreiner, A.C. Mahon, J.R. Nambu, M. Schaefer, and R. Taussig. 1984. Neuropeptides: Mediators of behavior in Aplysia. Science 225: 1300-1308.

Scholnick, S., B.A. Morgan, and J. Hirsh. 1983. The cloned dopa decarboxylase gene is developmentally regulated when reintegrated into the Drosophila germline. Cell 34: 37-45.

Scholnick, S.B., S.J. Bray, B.A. Morgan, C.A. McCormick, and J. Hirsh. 1986. Distinct central nervous system and hypoderm regulatory elements of the $D$. melanogaster dopa decarboxylase gene. Science 234: 998-1002.

Shermoen, A.W., J. Jongens, S.W. Barnett, K. Flynn, and S.K. Beckendorf. 1987. Developmental regulation by an enhancer from the Sgs-4 gene of Drosophila. EMBO I. 6: 207-214.

Simon, J.A., C.A. Sutton, R.B. Lobell, R.L. Glaser, and J.T. Lis. 1985. Determinants of heat shock-induced chromosome puffing. Cell 40: 805-817.

Spofford, J.B. 1976. Position-effect variegation in Drosophila. In The genetics and biology of Drosophila vol. $2 a$ (ed. M. Ashburner and E. Novitski|, p.955-1018. Academic Press, New York.

Stanley, K.K. and J.P. Luzio. 1984. Construction of a new family of high efficiency bacterial expression vectors: Identification of cDNA clones coding for human liver proteins. EMBO $J$. 3: $1429-1434$.

Swanson, L.W., D.M. Simmons, J. Arriza, R.E. Hammer, R. Brinster, M.G. Rosenfeld, and R.M. Evans. 1985. Novel developmental specificity in the nervous system of transgenic animals expressing growth hormone fusion genes. Nature 317: 363-366.

Vallés, A.M. and K. White. 1986. Development of serotonincontaining neurons in Drosophila mutants unable to synthesize serotonin. I. Neurosci. 6: 1482-1490.

White, K. and A.M. Vallés. 1985. Immunohistochemical and genetic studies of serotonin and neuropeptides in Drosophila. In Molecular basis of neural development led. G.M. Edelman, W.E. Gall, and W.M. Covan), pp. 547-563. Wiley, New York.

Wright, T.R.F. 1987. The genetics of biogenic amine metabolism, sclerotization, and melanization in Drosophila melanogaster. Adv. Genet. 25 (in press).

Wright, T.R.F., R.B. Hodgetts, and A.F. Sherald. 1976. The genetics of dopa decarboxylase in Drosophila melanogaster. I. Isolation and characterization of deficiencies that delete the dopa-decarboxylase dosage sensitive region and the alphamethyl-dopa-hypersensitive locus. Genetics 84: 267-285.

Wright, T.R.F., B.C. Black, C.P. Bishop, J.L. Marsh, E.S. Pentz, R. Steward, and E.Y. Wright. 1982. The genetics of dopa decarboxylase in Drosophila: V. Ddc and l(2)amd alleles: Isolation, characterization and intragenic complementation. Mol. Gen. Genet. 188: 18-26. 


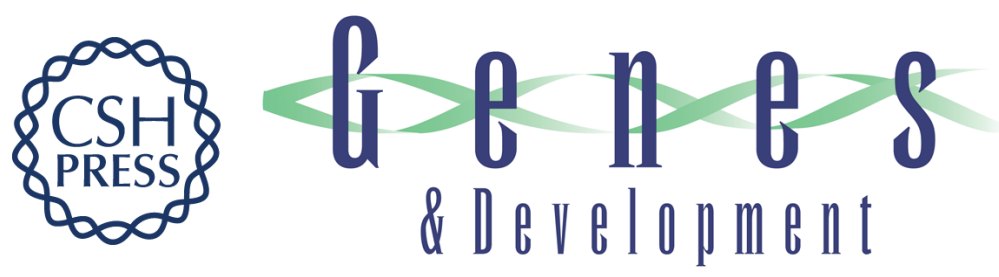

\section{Regulation of the Drosophila dopa decarboxylase gene in neuronal and glial cells.}

C J Beall and J Hirsh

Genes Dev. 1987, 1:

Access the most recent version at doi:10.1101/gad.1.5.510

References This article cites 25 articles, 11 of which can be accessed free at:

http://genesdev.cshlp.org/content/1/5/510.full.html\#ref-list-1

License

Email Alerting Receive free email alerts when new articles cite this article - sign up in the box at Service the top right corner of the article or click here.

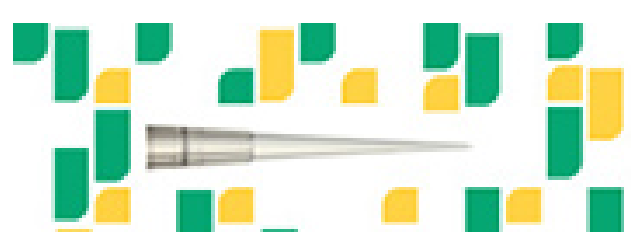

Focused on your science.

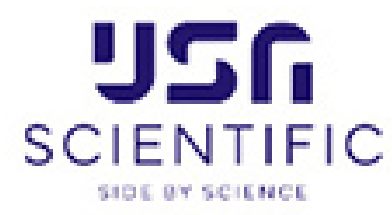

Copyright @ Cold Spring Harbor Laboratory Press 